\title{
Budesonide MMX in the Treatment of Ulcerative Colitis: Current Perspectives on Efficacy and Safety
}

This article was published in the following Dove Press journal:

Therapeutics and Clinical Risk Management

\section{Giovanni Maconi $(\mathbb{D}$ \\ Deborah Camatta \\ Rosanna Cannatelli \\ Francesca Ferretti \\ Anna Carvalhas Gabrielli \\ Sandro Ardizzone (D)}

Gastroenterology Unit, Department of Biomedical and Clinical Sciences FBF - L. Sacco, University Hospital, Milan, Italy
Correspondence: Giovanni Maconi Gastroenterology Unit, Department of Biomedical and Clinical Sciences, ASST Fatebenefratelli-Sacco University Hospital, University of Milan, Italy $\mathrm{Tel}+390239043164$

Fax +390239042232 Correspondence Email giovanni.maconi@unimi.it

\begin{abstract}
Budesonide MMX is a low bioavailability corticosteroid oral once-daily formulation, which has a controlled rate of release throughout the colon, thanks to the multimatrix (MMX) formulation. It has been available for a decade in the USA and Europe for the induction of remission in patients with active, mild to moderate ulcerative colitis, particularly for those not responsive to mesalamine. The efficacy of budesonide MMX in this setting has been assessed by registrative randomized controlled trials showing a higher rate of clinical and endoscopic remission at 8 weeks compared with placebo, mostly in patients with proctosigmoiditis and left-side colitis. Since it is available in our therapeutic armamentarium, a few studies have confirmed the effectiveness of budesonide MMX also in real-life, highlighting the high rate of clinical response and remission and the high safety profile. In the present review, we summarise clinical trials and real-life results of budesonide MMX, assessing its use and predictors of response and non-response in real-life.
\end{abstract}

Keywords: budesonide MMX, ulcerative colitis, efficacy, effectiveness, safety

\section{Introduction}

Ulcerative colitis (UC) is a chronic inflammatory bowel disease characterised by flares mainly presenting with diarrhoea, rectal bleeding and urgency, alternating with periods of remission. The main goal of therapy is treating the active disease to achieve clinical and endoscopic remission, and maintain long-term remission. ${ }^{1}$

The treatment of active ulcerative colitis is generally guided by the severity, extension and pattern of the disease, which includes relapse frequency, disease course, response to previous medications and extraintestinal manifestations. Conventional corticosteroids and biologics (anti-TNF alpha, vedolizumab, ustekinumab and tofacitinib) are currently available therapies for the induction of clinical remission, in particular for severe and refractory active UC. However, for mild-to-moderate (defined as Ulcerative Colitis Disease Activity Index-UCDAI score 4-10) relapses of the disease, when 5-aminosalicylic acid (5-ASA) treatment is not sufficient to achieve clinical remission, low-bioavailability corticosteroid formulations are now available. ${ }^{2}$

In this case, locally acting corticosteroids with low bioavailability and little systemic absorption, such as budesonide and beclomethasone, may be a valid alternative to systemic corticosteroids and biologics. ${ }^{3}$ A number of randomised clinical trials and real-life studies have shown the efficacy, effectiveness and safety of budesonide MMX in inducing remission in mild-to-moderate UC. 
This narrative review aims to summarize the evidence about the efficacy, effectiveness and safety of budesonide MMX, where efficacy is the performance of an intervention under ideal and controlled circumstances such as randomised controlled studies (RCTs), whereas effectiveness refers to its performance under "real-world" conditions.

We systematically searched the PubMed and Embase bibliographic databases for all articles published up to December 2020 combining the terms "Budesonide" and "Ulcerative colitis". We found 291 articles, 51 were pertinent (clinical trials, systematic reviews and metanalysis) and 14, specifically about budesonide MMX, were considered for this review.

\section{Budesonide MMX: Pharmacological Features}

Budesonide is a synthetic glucocorticosteroid similar to prednisolone but with 15 times greater affinity for the glucocorticoid receptor and higher topical activity. Moreover, it has lower bioavailability due to high firstpass liver metabolism (90\%), which means less hypothalamic-pituitary-adrenal axis suppression and fewer sideeffects compared to prednisolone.

Budesonide is currently available in different oral formulations: ${ }^{4}$ 1) controlled ileocolonic-release formulation (CIR) characterized by $\mathrm{PH}$ and time-dependent release, 2) $\mathrm{pH}$ dependent-release formulation, 3) multimatrix (MMX) formulation.

While ileal-release and $\mathrm{pH}$-dependent-release formulations are released in terminal ileum and ascending colon and are mainly used for induction of remission of mild-tomoderate Crohn's disease, budesonide MMX is the formulation approved for the treatment of mild-to-moderate UC. ${ }^{5}$ Capsules are composed by lipophilic and hydrophilic excipients enclosed within a gastro-resistant $\mathrm{pH}$-dependent coating. This pharmaceutical formulation enables homogeneous distribution of the active drug along the colonic segments, particularly distal ones. In fact, it avoids the release until the tablet is exposed at a $\mathrm{pH}>7$, which is reached in the terminal ileum, so that the active drug plays its therapeutic role directly on the colonic mucosa. Pharmacokinetic studies showed that the mean absorption of budesonide MMX in the region between ascending and descending colon was $95.5 \%$, with drug detected in the mucosa between 4 and 24 hours post-dose, ${ }^{5}$ showing how MMX technology enables the drug to reach exactly its target. Another advantage of this formulation is the single daily dose, which increases the patient's adherence to the therapy. ${ }^{4}$ Moreover, the dose is the same for all the treatment and does not need to be reduced.

\section{Budesonide MMX - Randomised Controlled Studies \\ Efficacy}

The primary endpoint of all RCTs performed so far, was the assessment of efficacy and safety of budesonide MMX for induction of remission of mild-to-moderate UC, namely the clinical and endoscopic remission after 8 weeks of treatment.

Among those, CORE (Colonic Release Budesonide) I by Sandborn et $\mathrm{al}^{6}$ and CORE II by Travis et $\mathrm{al}^{7}$ were two identically designed randomized trials comparing budesonide MMX $9 \mathrm{mg}$ and $6 \mathrm{mg}$ with mesalamine 2.4 $\mathrm{g}$ and placebo (CORE I) or with budesonide CIR $9 \mathrm{mg}$ and placebo (CORE II), respectively. In both studies, the treatment schedule was 8 weeks and the primary endpoint was clinical and endoscopic remission at week 8 , defined as UCDAI score $\leq 1$ with score of 0 of rectal bleeding and stool frequency, no mucosal friability on colonoscopy and reduction of $\geq 1$ point in endoscopic index score from baseline. ${ }^{5}$ In both studies clinical and endoscopic remission was achieved in a significantly greater percentage of patients receiving budesonide MMX compared with placebo $(17.9 \%$ vs $7.4 \%, \mathrm{p}=0.0143$ in CORE I, $17.4 \%$ vs $4.5 \%, \mathrm{p}=0.005$ in CORE II) (Table 1).

In particular, in CORE $\mathrm{I}^{6}$ this difference remained statistically significant after adjusting for age, sex and geographic region. This benefit was significantly higher for left-sided colitis $(31.3 \%$ vs $5.9 \%, \mathrm{p}=0.0076)$ and numerically higher for proctosigmoiditis. However, for extensive disease no significant differences in clinical and endoscopic remission rate were observed.

The secondary endpoints of CORE I study, namely clinical and endoscopic improvement of patients, showed that the rates of clinical improvement at week 8 among patients given $9 \mathrm{mg}$ or $6 \mathrm{mg}$ budesonide MMX, or mesalamine, were $33.3 \%, 30.6 \%$ and $33.9 \%$ respectively, compared with $24.8 \%$ for placebo (P: n.s.) (Table 1) and that the rates of endoscopic improvement at week 8 among patients given $9 \mathrm{mg}$ or $6 \mathrm{mg}$ budesonide MMX or mesalamine were $41.5 \%, 35.5 \%$ and $33.1 \%$ respectively, compared with $33.1 \%$ for placebo (P: n.s.).

In CORE $\mathrm{II}^{7}$ clinical and endoscopic remission rates with budesonide MMX $9 \mathrm{mg}$ for left-sided disease were 
Table I Main Features and Results of Clinical Studies of Budesonide (BUD) MMX 9 mg, Compared with Placebo, at Week 8 in Ulcerative Colitis (Intention to Treat Analysis)

\begin{tabular}{|c|c|c|c|c|c|}
\hline Author, Year & Study Design & $\begin{array}{l}\text { Number of } \\
\text { Patients }\end{array}$ & $\begin{array}{l}\text { Clinical } \\
\text { Improvement }\end{array}$ & $\begin{array}{l}\text { Clinical } \\
\text { Remission }\end{array}$ & Side Effects \\
\hline $\begin{array}{l}\text { Sandborn, } \\
2012^{6}\end{array}$ & $\begin{array}{l}\text { RCT } \\
\text { BUD } 9 \mathrm{mg} \text { vs placebo }\end{array}$ & 123 vs $12 \mid$ & $33.3 \%$ vs $24.8 \%$ & $17.9 \%$ vs $7.4 \%$ & $\begin{array}{l}28.3 \% \text { vs } \\
26.4 \% \S\end{array}$ \\
\hline Travis, $2014^{7}$ & $\begin{array}{l}\text { RCT } \\
\text { BUD } 9 \mathrm{mg} \text { vs placebo }\end{array}$ & 109 vs 129 & $42.2 \%$ vs $33.7 \%$ & $\begin{array}{l}23.9 \% \text { vs } 11.2 \% \\
17.4 \% \text { vs } 4.5 \% *\end{array}$ & $\begin{array}{l}55.5 \% \text { vs } \\
44.2 \%\end{array}$ \\
\hline Rubin $2017^{9}$ & $\begin{array}{l}\text { RCT } \\
\text { BUD } 9 \mathrm{mg} \text { vs placebo }\end{array}$ & 230 vs 228 & $47.0 \%$ vs $39.0 \% \S$ & $\begin{array}{l}24.3 \% \text { vs } 22.8 \% \oint \\
13.0 \% \text { vs } 7.5 \% *\end{array}$ & $\begin{array}{l}31.8 \% \text { vs } \\
27.1 \% \S\end{array}$ \\
\hline $\begin{array}{l}\text { D'Haens } \\
2010^{17}\end{array}$ & $\begin{array}{l}\text { Prospective multicentre study } \\
\text { BUD } 9 \mathrm{mg} \text { vs placebo }\end{array}$ & 18 vs 18 & $47.6 \%$ vs $33.3 \%^{\S \#}$ & n.a. & n.a. \\
\hline Danese, $2016^{13}$ & $\begin{array}{l}\text { Prospective multicentre observational } \\
\text { study }\end{array}$ & 326 & $60.1 \%$ & $51.8 \%$ & $17.5 \%$ \\
\hline Maconi, $2019^{14}$ & Retrospective study, multicentre study & 89 & $52.4 \%$ & $50 \%$ & $30.5 \%$ \\
\hline $\begin{array}{l}\text { Fellerman, } \\
2020^{16}\end{array}$ & $\begin{array}{l}\text { Prospective multicentre observational } \\
\text { study }\end{array}$ & 61 & $60.7 \%$ & $47.5 \%$ & $39.3 \%$ \\
\hline
\end{tabular}

Notes: RCT, randomised clinical trial. *Clinical remission plus endoscopic remission. ${ }^{\S}$ Not significant. ${ }^{\#}$ Clinical remission at 4 weeks.

Abbreviations: n.a., not available.

significantly higher than the placebo $(17.7 \%$ vs $5.8 \%, \mathrm{p}=$ 0.03 ), while in the extensive disease group the combined remission rate with budesonide MMX was numerically higher but not statistically significant (Table 1). Moreover, significantly more patients achieved histological healing and complete symptom resolution with budesonide MMX $9 \mathrm{mg}$ compared to the placebo.

In a pooled analysis of CORE I and CORE II performed by Sandborn et al, ${ }^{8}$ patients treated with budesonide MMX $9 \mathrm{mg}$ were 3 times more likely to achieve clinical and endoscopic remission compared to placebo (OR 3.3, 95\% CI 1.7-6.4). In this study, budesonide MMX 9 mg was significantly more efficacious than placebo in various subgroups, including males, females, patients aged $\leq 60$ years, patients with and without prior 5-ASA use, patients with mild and moderate disease activity, patients with left-sided colitis and proctosigmoiditis.

Efficacy and safety of budesonide MMX in patients with mild-to-moderate UC on concomitant therapy with mesalamine $\geq 2.4 \mathrm{~g} /$ day were assessed in a randomized, double-blind, placebo controlled, multicenter trial by Rubin et al. ${ }^{9}$ In this study, 510 adults with mild-tomoderate UC were treated with budesonide MMX $9 \mathrm{mg}$ or placebo for 8 weeks, continuing baseline treatment with mesalamine. Combined clinical and endoscopic remission at week 8 was reached in a significantly greater percentage in patients receiving budesonide MMX compared with placebo $(13 \%$ vs $7.5 \%, \mathrm{p}=0.049)$ while clinical remission rate was similar in both groups $(24.3 \%$ vs $22.8 \%, \mathrm{p}=$ 0.70). More patients treated with budesonide MMX vs placebo reached endoscopic remission $(20 \%$ vs $12.3 \%$, $\mathrm{p}=0.02)$ and histological healing $(27 \%$ vs $17.5 \%$, $\mathrm{p}=0.02)$.

These data are in keeping with a Cochrane review. ${ }^{10}$ Pooled data from the described RCTs, ${ }^{6,7,9}$ which included a total of 900 patients, showed that budesonide MMX $9 \mathrm{mg}$ daily was twice as effective as the placebo for induction of combined clinical and endoscopic remission at 8 weeks (RR $2.25 ; 95 \%$ CI 1.50 to 3.39). A subgroup analysis based on disease location suggested that budesonide provided the most benefit in patients with left sided colitis (RR 2.98, 95\% CI 1.56 to 5.67) compared to those with pancolitis (RR 2.42, 95\% CI 0.61 to 9.56 ).

\section{Safety}

Thanks to its local effect and low systemic bioavailability, budesonide MMX is generally well tolerated. The most common treatment-emergent adverse events (AE) in CORE $\mathrm{I}^{6}$ and CORE $\mathrm{II}^{7}$ were, in frequency order, UC relapse (11.8\% and $14.6 \%$ vs $9.6 \%$ in placebo groups), headache ( $4.5 \%$ and $4.7 \%$ vs $4.1 \%$ in placebo group) and nausea. In both studies, the number of patients with severe 
AEs and leading to discontinuation of treatment was similar across all the treatment groups. In particular, in CORE I the percentage of patients with severe AEs was highest in the placebo group (12.4\%) compared to the budesonide MMX $9 \mathrm{mg}$ group (6.3\%), budesonide MMX $6 \mathrm{mg}$ group (9.5\%) and Asacol group (5.5\%). In Rubin's study ${ }^{9}$ the safety of budesonide MMX was confirmed also when combined with mesalamine, with a total of AEs in $31.8 \%$ and $27.1 \%$ of patients receiving budesonide $\mathrm{MMX}$ or placebo (the most common AE was UC relapse in both groups).

As for the potential specific glucocorticoids side-effects of these trials (in frequency order: mood changes, sleep changes, insomnia, moon face, striae rubrae, flushing, fluid retention, acne, hirsutism), these occurred in similar percentage across all study groups, and the mean morning cortisol values remained within the normal limits in all the treatment groups. $^{6,7,9}$

A pooled safety data analysis ${ }^{11}$ of randomised, double blind, placebo controlled trials and of an open-label study, confirmed that budesonide MMX showed a good compliance $(>80 \%)$ and a percentage of AEs similar to that of placebo, with an incidence of potential glucocorticoid-related adverse effects $<10 \%$, without any apparent dose-related effect.

These data are in keeping with those of a systematic review and metanalysis (31 trials and 5689 patients), which assessed the safety of systemic and lowbioavailability steroids in inflammatory bowel disease. This study highlighted the good safety profile of budesonide MMX, with significantly fewer corticosteroid-related AEs than oral systemic corticosteroids (OR 0.25, 95\% CI 0.13 to 0.49 ) or beclomethasone (OR $0.35,95 \%$ CI 0.13 to 1.00), and with fewer, although not significantly, AEs than budesonide (OR $0.64,95 \%$ CI 0.37 to 1.11 ). ${ }^{12}$

\section{Budesonide MMX - Real-Life Studies \\ Effectiveness}

The real-life studies on budesonide MMX have confirmed the benefit on symptoms in active mild-to-moderate UC, already observed in the randomised controlled studies, showing in addition an improvement in quality of life.

A real-life multicentre observational prospective cohort study conducted in Europe and Canada assessed budesonide MMX effectiveness in induction of remission of mild-to-moderate UC as in monotherapy or as add-on therapy to $5-\mathrm{ASA}^{13}$ (Table 1 ). The primary endpoint of this study was the clinical benefit of the therapy, defined as improvement $\geq 3$ points in UCDAI score at the end of induction treatment and was reached by $60.1 \%$ of patients. Secondary endpoints were clinical remission (UCDAI score $\leq 1$ ), symptoms resolution, percentage of patients with full symptoms resolution (absence of rectal bleeding normalization of bowel habit and no urgency), time to symptoms resolution, change in health-related quality of life, and objective signs of inflammation, such as percentage of patients with endoscopic healing and faecal calprotectin within the normal range. Clinical remission was achieved in $51.8 \%$ of patients, symptoms resolutions and full symptoms resolution in $63.2 \%$ and $45.1 \%$ of patients, and the median time to symptoms resolution was 30 days. Improvement in quality of life (assessed by Short Inflammatory Bowel Disease Questionnaire, SIBDQ) was observed in all the cohort of patients, particularly in those in whom budesonide MMX was added to mesalazine as a late add-on (11 points) or early add-on (14 points), and less in those it was prescribed as monotherapy ( 7 points). Unfortunately, no objective signs of inflammation can be given because of lack of data in this cohort of patients. Rectal bleeding and Physicians's Global Assessment at baseline visit, high compliance to treatment were independently associated with a higher probability of achieving clinical benefit at multivariable analysis.

Effectiveness of budesonide MMX in real life practice was assessed by another Italian multicentre retrospective cohort study. ${ }^{14}$ In this study 82 patients with mild-tomoderate UC were treated with budesonide MMX for 8 weeks (with or without concomitant therapy with 5-ASA, immunosuppressant or biologics). The primary endpoints of this study, namely the clinical remission after 2 months (defined as Partial Mayo Clinic Score of 0-1 with rectal bleeding sub-score 0) and clinical response (reduction of Partial Mayo Score $>3$ points and $>30 \%$ compared with baseline), were achieved in $50 \%$ and $52.4 \%$ of patients, respectively (Table 1). Most responder patients had proctitis or left-side colitis, were not receiving biologic or immunosuppressant therapy, and were affected by a mild disease.

In particular, the study showed a low adherence and compliance to budesonide MMX therapy as three patients did not start therapy and $25 \%$ of patients discontinued treatment before completing the schedule, most likely because of the quick improvement of symptoms. In this study, the predictors of clinical response to budesonide MMX have been assessed by univariate and multivariate binary logistic regression, which identified concomitant therapy with biologics and immunosuppressants and 
degree of disease activity as independent predictors of non-response. Moreover, clinical remission was achieved in $75 \%$ of patients with mild disease, limited to left-sided colitis or proctitis who had never been treated with biologics or immunosuppressants, while age, sex, comorbidities, duration of $\mathrm{UC}$, use of topical therapy and indication of budesonide MMX were not associated with achieving the primary outcome.

In another real life study, Greenberg et $\mathrm{al}^{15}$ focused at identifying predictors of inadequate response to budesonide MMX in patients with UC. This retrospective study enrolled 96 patients with mild-to-moderate UC treated with budesonide MMX with or without 5-ASA, immunomodulators or biologic therapy. The failure of treatment, defined as step-up to prednisone as a rescue therapy due to the inadequate clinical response to budesonide MMX, occurred in $46 \%$ of patients and was significantly more frequent in male sex and younger age ( $<29$ years old) at diagnosis. On the contrary, previous or current therapies (including biologics), Mayo score at baseline and disease extent were not predictors of failure of therapy.

Furthermore, TOPICAL- $1^{16}$ is another multicentre study, which assessed efficacy and safety of budesonide MMX in 61 patients with mesalamine refractory UC. The patients were treated with budesonide MMX $9 \mathrm{mg}$ for 8 weeks after discontinuing mesalamine, followed by 2 weeks of treatment on alternate days. Primary endpoint was clinical remission at week 8 (Clinical Activity Index $\leq 4$, bowel movements $<18$ per week, absence of rectal bleeding) and secondary endpoints were clinical, endoscopic and histological features at week 8. Clinical remission was achieved in $47.5 \%$ patients $(95 \%$ CI 34.6-60.7\%), and bowel movements and bloody stool frequency significantly decreased (from 32.5 to 22.9 per week and from 17.1 to 8.1 per week, respectively). Rates of mucosal healing, endoscopic remission and histological remission were $58 \%, 54 \%$ and $36 \%$, respectively. Histological and endoscopic mucosal healing was achieved by $34 \%$ of patients.

For completeness, in a prospective multicenter study, D'Haens et al investigated 36 patients with active, leftsided UC (activity index $(\mathrm{CAI})<14)$ who were treated once daily for 4 weeks with Budesonide-MMX ${ }^{\circledR} 9 \mathrm{mg}$ tablets or placebo followed by an additional 4-week period with Budesonide-MMX ${ }^{\circledR}$. The primary end-point, namely the remission and/or CAI reduction by $50 \%$ after 4 weeks, was achieved by $47.1 \%$ of the patients on Budesonide$\mathrm{MMX}^{\circledR}$ and by $33.3 \%$ of patients on placebo, with a significant CAI reduction only with Budesonide $(p<0.0001)$ not with placebo $(p=0.1){ }^{17}$

\section{Safety}

Budesonide MMX is well tolerated, as shown by RCTs and real life studies. In a previous study, we ${ }^{14}$ reported 8 significant adverse effects (facial hirsutism, constipation and tenesmus, hypertensive crisis, iatrogenic Cushing's syndrome, headache, acne and insomnia) in 6 of 82 patients $(7.3 \%)$, but only 3 so severe to discontinue treatment. In Danese et al study, ${ }^{13} 24 \%$ of patients reported at least one adverse effect, mainly the ineffectiveness of treatment $(12 \%)$, and no major systemic steroids side effects were observed.

In TOPICAL-1 study ${ }^{16} 39.3 \%$ of patients experienced adverse events during the 8 weeks of budesonide MMX treatment, and $13.1 \%$ discontinued the treatment. The most common adverse events were flares of UC (13.1\%), headache $(6.6 \%)$ and respiratory tract infections (3.3\%). Fewer patients experienced adverse events during follow-up, suggesting that tapering the dose of budesonide MMX may be associated with a favourable safety profile. Mean cortisol levels remained stable within the normal range during the treatment and follow-up phase.

\section{Topical Budesonide}

UC patients complain of symptoms, such as urgency, tenesmus, incontinence and rectal bleeding, which are frequently related to distal inflammation, and up to $60 \%$ of patients have a disease confined to the rectum or distal colon. As a consequence, topical therapies are important adjunctive treatments in UC.

The topical mesalazine, either as enema, foam or suppositories, is the mainstay treatment for mild to moderately active proctitis, left-sided or distal colitis, but also corticosteroid treatments such as beclomethasone dipropionate and more recently budesonide have been introduced for these indications.

Topical budesonide formulations have been proved very effective in treating active distal forms of UC. The latest systematic review and meta-analysis of randomized placebo-controlled trials, which included 3 randomized placebo-controlled trials and 711 patients with mild-tomoderate distal UC, showed that budesonide foam was significantly superior to placebo for the induction of clinical remission (95\% CI: 1.41, 2.37) and endoscopic improvement (95\% CI: 1.23, 1.68), and eliminating rectal bleeding at week 2 (95\% CI: 1.50, 2.66), week 4 (95\% CI: 
$1.42,2.12)$, and week 6 (95\% CI: 1.45, 2.14). ${ }^{18}$ A more recent pooled analysis of two clinical Japanese studies, including 291 patients, showed that at week 6, budesonide foam provided a significantly greater achievement rate than placebo of elimination of rectal bleeding $(65.5 \%$ vs $36.8 \%$ ), clinical remission (44.5\% vs $17.9 \%$ ) and complete mucosal healing $(39.5 \%$ vs $4.3 \%) .{ }^{19}$ Other randomised studies showed that it has a similar efficacy to that of rectal mesalazine. ${ }^{20,21}$

So far, among the different budesonide topical formulations, the budesonide foam seems to be preferrable because of optimised drug spread and retention, a standardized delivery and a wider acceptance by patients compared with enema. ${ }^{22,23}$ Budesonide suppositories have also been shown as an effective alternative therapy to mesalamine for topical treatment of proctitis. A recent multicenter randomised study showed that $4 \mathrm{mg}$ budesonide suppositories provided proportions of patients with deep, clinical, and endoscopic remission, as well as mucosal healing, comparable to that of $1 \mathrm{~g}$ mesalazine. ${ }^{21}$

\section{Conclusions}

The current evidences show efficacy and effectiveness in a short term ( 8 weeks), but leave some questions still unanswered, particularly regarding the position on treatment.

It is clear that the main indication of budesonide treatment is mild to moderate UC. However, it could be questionable if this should be used as first choice instead of high dose mesalamine, as suggested in randomised studies CORE I and CORE II ${ }^{6,7}$ or as an add-on to mesalazine (or biologics and immunosuppressants) in refractory patients, as suggested in the Rubin's study ${ }^{9}$ and in most real-life studies. ${ }^{13-15}$ The results of these studies showed that both clinical contexts are appropriate indications for budesonide MMX treatment, with clinical benefit in most patients treated, ranging from $33 \%$ to $47 \%$ in randomised trials, and in more than half of patients $(52-61 \%)$ in real-life (Table 1).

In particular, a consensus meeting about the i-Support Therapy-Access to Rapid Treatment (iSTART) approach in patients with mild-to-moderate UC that experienced a flare during therapy with 5-ASA recommended the use of oral budesonide MMX as soon as possible, with a strong agreement of $81.8 \%$ of the participants. ${ }^{24}$

Moreover, data emerging from these studies showed that there are specific features, such as left-sided colitis and proctosigmoiditis, ${ }^{6-9}$ rectal bleeding and an overall good
Physicians' Global Assessment, ${ }^{13}$ that represent predictors of response to treatment. On the contrary, factors such male sex, young age and more severe disease, characterised by extensive colitis, high degree of disease activity and treatment with immunosuppressants or biologics, may suggest less chance of benefit from the treatment (Table 2). These data could help to choose a better "personalized" treatment.

Currently, in the era of evidence based clinical practice, we are strongly recommended to follow the clinical guidelines. $^{25}$ Therefore, Budesonide MMX is mainly used in UC patients with mild to moderate ulcerative colitis in whom mesalazine induction therapy fails or is not tolerated, in order to avoid treatment with systemic corticosteroids. However, the presence in these patients of predictors of poor efficacy such as extensive colitis, higher disease activity, concomitant immunosuppressive therapies, allows us to also consider alternative and newer therapies such as biologics or JAK inhibitors.

Finally, the long-term outcome of budesonide MMX after induction treatment remains to be investigated. Given the high safety profile, and absence of steroid related side effects, it could be hypothesized to prolong treatment after 4 months as a maintenance therapy, at least up to 6 months or up to achieve a stable remission of the disease to guarantee a better outcome after withdrawal of therapy. This is what happened in our real-life study, ${ }^{14}$ and still happens in some patients in our clinical practice, particularly when treatment is effective and well tolerated, and safe alternative medical treatments are missing. Additional studies are needed to further investigate these aspects.

Table 2 Predictors of Response and Non-Response to Budesonide MMX Therapy

\begin{tabular}{|l|l|}
\hline $\begin{array}{l}\text { Predictors of } \\
\text { Response }\end{array}$ & Predictors of Non-Response \\
\hline Left-sided colitis[6] & Extensive colitis[6,7] \\
\hline Rectal bleeding[13] & $\begin{array}{l}\text { Concomitant therapy with biologics and } \\
\text { immunosoppressants[14] }\end{array}$ \\
\hline $\begin{array}{l}\text { Physicians' Global } \\
\text { Assessment[13] }\end{array}$ & Degree of disease activity[14] \\
\hline $\begin{array}{l}\text { Compliance to } \\
\text { treatment[13] }\end{array}$ & Male sex[15] \\
\hline \multicolumn{2}{|l}{ Age $<29[15]$} \\
\hline
\end{tabular}




\section{Disclosure}

Dr Giovanni Maconi reports personal fees from Janssen Cilag, Roche, Gilead, and Alfa Sigma, outside the submitted work. The authors report no other conflicts of interest in this work.

\section{References}

1. Magro F, Gionchetti P, Eliakim R, et al. Third European evidence-based consensus on diagnosis and management of ulcerative colitis. Part 1: definitions, diagnosis, extra-intestinal manifestations, pregnancy, cancer surveillance, surgery, and ileo-anal pouch disorders. J Crohns Colitis. 2017;11(6):649-670.

2. Harbord M, Eliakim R, Bettenworth D, et al. Third European evidence-based consensus on diagnosis and management of ulcerative colitis. Part 2: current management. J Crohns Colitis. 2017;11 (7):769-784.

3. D'Haens G. Systematic review: second-generation vs. conventional corticosteroids for induction of remission in ulcerative colitis. Aliment Pharmacol Ther. 2016;44(10):1018-1029. doi:10.1111/ apt.13803

4. Nardelli S, Pisani LF, Tontini GE, Vecchi M, Pastorelli L. MMX ${ }^{\circledR}$ technology and its applications in gastrointestinal diseases. Ther Adv Gastroenterol. 2017;10(7):545-552. doi:10.1177 1756283 X17709974

5. Lichtenstein GR. Budesonide multi-matrix for the treatment of patients with ulcerative colitis. Dig Dis Sci. 2016;61(2):358-370. doi:10.1007/s10620-015-3897-0

6. Sandborn WJ, Travis S, Moro L, et al. Once-daily budesonide $\mathrm{MMX}^{\circledR}$ extended-release tablets induce remission in patients with mild to moderate ulcerative colitis: results from the CORE i study. Gastroenterology. 2012;143(5):1218-1226.e2. doi:10.1053/j. gastro.2012.08.003

7. Travis SPL, Danese S, Kupcinskas L, et al. Once-daily budesonide MMX in active, mild-to-moderate ulcerative colitis: results from the randomised CORE II study. Gut. 2014;63(3):433-441. doi:10.1136/ gutjnl-2012-304258

8. Sandborn WJ, Danese S, D'Haens G, et al. Induction of clinical and colonoscopic remission of mild-to-moderate ulcerative colitis with budesonide MMX $9 \mathrm{mg}$ : pooled analysis of two Phase 3 studies. Aliment. Pharmacol. Ther. 2015;41(5):409-418. doi:10.1111/apt.13076

9. Rubin DT, Cohen RD, Sandborn WJ, et al. Budesonide multimatrix is efficacious for mesalamine-refractory, mild to moderate ulcerative colitis: a randomised, placebo-controlled trial. J Crohns Colitis. 2017;11(7):785-791. doi:10.1093/ecco-jcc/jjx032

10. Sherlock ME, Macdonald JK, Griffiths AM, Steinhart AH, Seow CH. Oral budesonide for induction of remission in ulcerative colitis. Cochrane Database Syst Rev. 2015;2015(10).

11. Lichtenstein GR, Travis S, Danese S, et al. Budesonide MMX for the induction of remission of mild to moderate ulcerative colitis: a pooled safety analysis. J Crohns Colitis. 2015;9(9):738-746. doi:10.1093/ ecco-jcc/jjv101

12. Bonovas S, Nikolopoulos GK, Lytras T, Fiorino G, Peyrin-Biroulet L, Danese S. Comparative safety of systemic and low-bioavailability steroids in inflammatory bowel disease: systematic review and network meta-analysis. Br J Clin Pharmacol. 2018;84(2):239-251. doi: $10.1111 /$ bcp. 13456
13. Danese S, Hart A, Dignass A, et al. A multicentre prospective cohort study assessing the effectiveness of budesonide MMX $^{\circledR}$ (Cortiment ${ }^{\circledR}$ $\mathrm{MMX}^{\circledR}$ ) for active, mild-to-moderate ulcerative colitis. United Eur Gastroenterol J. 2019;7(9):1171-1182. doi:10.1177/ 2050640619864848

14. Maconi G, Mezzina N, Landi S, et al. Use, effectiveness and tolerability of budesonide-MMX in ulcerative colitis: a real-life experience. United Eur. Gastroenterol. J. 2019;7(9):1164-1170. doi:10.1177/2050640619864257

15. Greenberg S, Herfarth HH, Barnes EL. Predictors of inadequate response to budesonide multimatrix in real-world patients with ulcerative colitis. Inflamm Intest Dis. 2019;4(3):115-122. doi:10.1159/000501004

16. Fellermann K, Schiefke I, Rácz I, et al. Efficacy and safety of prolonged release budesonide granules in mesalazine-refractory ulcerative colitis: a multi-centre Phase IIa study (TOPICAL-1). United Eur. Gastroenterol. J. 2020;8(10):1186-1195. doi:10.1177/ 2050640620962632

17. D'Haens GR, Kovács A, Vergauwe $\mathrm{P}$, et al. Clinical trial: preliminary efficacy and safety study of a new Budesonide-MMX ${ }^{\circledR} 9 \mathrm{mg}$ extended-release tablets in patients with active left-sided ulcerative colitis. J Crohns Colitis. 2010;4(2):153-160. doi:10.1016/j. crohns.2009.09.007

18. Zeng J, Lv L, Mei ZC. Budesonide foam for mild to moderate distal ulcerative colitis: a systematic review and meta-analysis. J Gastroenterol Hepatol. 2017;32:558-566. doi:10.1111/jgh.13604

19. Hibi T, Naganuma M, Oda E, et al. Predictive factors for achievement of mucosal healing by budesonide 2-mg foam in ulcerative colitis: a pooled analysis of data from two clinical trials. Intest Res. 2020;18 (1):56-68. doi:10.5217/ir.2019.00064

20. Lémann M, Galian A, Rutgeerts P, et al. Comparison of budesonide and 5-aminosalicylic acid enemas in active distal ulcerative colitis. Aliment Pharmacol Ther. 1995;9:557-562. doi:10.1111/j.13652036.1995.tb00421.x

21. Kruis W, Neshta V, Pesegova M, et al. Budesonide suppositories are effective and safe for treating acute ulcerative proctitis. Clin Gastroenterol Hepatol. 2019;17(1):98-106. doi:10.1016/j. cgh.2018.04.027

22. Gross V, Bar-Meir S, Lavy A, et al. Budesonide foam versus budesonide enema in active ulcerative proctitis and proctosigmoiditis. Aliment Pharmacol Ther. 2006;23(2):303-312. doi:10.1111/j.13652036.2006.02743.x

23. Brunner M, Vogelsang H, Greinwald R, et al. Colonic spread and serum pharmacokinetics of budesonide foam in patients with mildly to moderately active ulcerative colitis. Aliment Pharmacol Ther. 2005;22(5):463-470. doi:10.1111/j.1365-2036.2005.02571.x

24. Danese S, Banerjee R, Cummings JF, et al. Consensus recommendations for patient-centered therapy in mild-to-moderate ulcerative colitis: the i Support Therapy-Access to Rapid Treatment (iSTART) approach. Intest Res. 2018;16(4):522-528. doi:10.5217/ir.2018.00073

25. Lamb CA, Kennedy NA, Raine $T$, et al. British Society of Gastroenterology consensus guidelines on the management of inflammatory bowel disease in adults. Gut. 2019;68(Suppl 3):s1-s106. 


\section{Publish your work in this journal}

Therapeutics and Clinical Risk Management is an international, peerreviewed journal of clinical therapeutics and risk management, focusing on concise rapid reporting of clinical studies in all therapeutic areas, outcomes, safety, and programs for the effective, safe, and sustained use of medicines. This journal is indexed on PubMed Central, CAS,
EMBase, Scopus and the Elsevier Bibliographic databases. The manuscript management system is completely online and includes a very quick and fair peer-review system, which is all easy to use. Visit http://www.dovepress.com/testimonials.php to read real quotes from published authors. 